Ankara Ecz. Fak. Mec.

13. III (1983)
J. Fak. Pharm Ankara

13. III (1983)

\author{
Benzoik Asit Esteri Lokal Anestezik Bileşiklerin \\ Sentez ve Yapı Açıklamaları - I* \\ Synthesis and Structure Elucidation of Benzoic Acid \\ Esters Possessing Local Anesthetic Activity - I*
}

Tuncel ÖZDEN**

GİRİ̧ ve AMAÇ

Son yıllarda yapılan çalışmalarla ilaç etken bileşiklerinin kimyasal yapıları ile biyolojik etkileri arasındaki ilişkilerin kurulabilmesi ve böylece en etkili olabilecek bileşiğin kağıt üzerinde hesaplanarak sentezlenmesi sonucu gereksiz harcamalardan kaçınmak mümkün olabilmektedir. Ayrıca, yapı-etki ilişkileri çalışmaları sonucu etki mekanizması hakkında da bilgi alınabilmektedir.

$\mathrm{Bu}$ çalışmada, benzoik asit esteri lokal anestezik bileşikler ele alınmıştır. Bu tip bileşiklerden benzen halkasının meta ve para konumunda substituent içerenlerde etki, çeşitli fizikokimyasal parametrelerle açıklanabilmektedir. Ancak, orto konumunda sübstitüent içerenlerde etkinin sadece hidrofobik veya sadece elektronik parametrelerle açıklanması mümkün değildir, zira, bu konumdaki grup kimyasal olarak mezomerik ve indüktif etkisinin yanısıra sterik etki de oluşturmaktadir.

Redaksiyona Verildiği Tarih: 4 Nisan 1983

* "Benzoik Asit Esteri Lokal Anestezik Bileşiklerde Orto Konumunda Bulunan Sübstitüentlerin Biyolojik Etkiye Katkıları Yönünden İncelenmesi" isimli Doçentlik Tezinin bir bölümüdür. (Sınav Tarihi: Kasım 1980).

** Farmasötik Kimya Anabilim Dalı, Eczacılık Fakültesi, Ankara Üniversitesi. 
Orto konumunda bulunan grubun etkiyi nasıl yönlendirdiği, etki değişikliğinde hangi özelliklerinin rol oynadı̆̆ını ortaya koymak üzere, orto konumunda sübstitüent bulunduran türevlerin yanısıra, sadece para ve hem para hem de orto konumunda sübstitüe türevler hazırlanmış ve böylece orta konumunun etkiye katkısını ortaya koymak üzere karşılaştırmalı çalışma olanağı bulunmuştur. Çalışmanın bu bölümünde, sadece orto veya para konumundan sübstitüent içeren bileşiklerin sentez ve aletsel analiz yöntemleri ile yapı açıklamaları verilecektir.

\section{DENEYSEL KISIM}

Kimyasal Bileşikler: Çalışmada kullanılan tüm çözücüler (Merck, Aldrich, Riedel) teknik veya analitik niteliktedir. Sentez başlangıç bileşikleri dialkilaminler (Ega), 2-kloroetanol (Aldrich), o-metilbenzoik asit (Merck), orto ve parametoksi benzoik asit (Aldrich), orto ve paranitrobenzoik asit (Merck), orto ve paraaminobenzoik asit (Merck) arı bileşiklerdir.

Aletsel analiz çalışmalarında, spektral saflıkta potasyum bromür

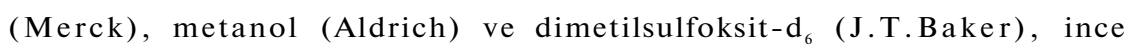
tabaka kromatografisi çalışmalarında ise adsorban olarak Kiselgel $\mathrm{HF}_{254}$ kullanılmıştır.

Elektronik Cihazlar: Aletsel analiz çalışmalarında Ultraviyole Spektrofotometresi (Pye Unicam SP 1700), İnfrared Spektrofotometresi (Pye Unicam SP 1100), N M R Spektrometresi (Varian T 60 A), Kütle Spektrometresi (Perkin Elmer RM-U-6E) ve Ergime Noktası Tayin Cihazı (Mettler FP 5 ve 51) kullanılmıştır.

\section{Dialkilaminoetanol Bileşiklerinin Sentezi (1-17)}

$500 \mathrm{ml}$ lik çift boyunlu bir balon içine 2.8 mol dialkilamin konuldu. Balonun bir boyununa geri çeviren soğutucu, diğerine ise damlatma hunisi takıldı. Balon içeriği geri çeviren soğutucu altında, yă banyosu ve manyetik karıştırıcı üzerinde 1sıtılmaya başlandı. Ya banyosunun isıs $80{ }^{\circ} \mathrm{C}$ olduğunda, 2 mol 2-kloroetanol damlatma hunisi aralı̆ğ ile balon içine aktarıldı ve karışım $130^{\circ} \mathrm{C}$ de 16 saat karıştırıldı. Bu süre, sonunda balon içeriği soğutuldu ve faz ayrılana 
kadar \% 30 luk sodyum hidroksit çözeltisi ilave edildi. Üst faz bir ayırma hunisi aracılığı ile alındı. Alt faz $3 \mathrm{kez} 50$ şer $\mathrm{ml}$ dietileter ile çalkalandı ve eterli tabakalar üst faz ile birleştirildi. Oda ısısında distilasyon ile eter ortamdan uzaklaştırıldı ve kalıntıya $10 \mathrm{~mm}$ civarındaki cıva basıncı altında fraksiyonlu distilasyon işlemi uygulanarak saf bileşikler elde edildi.

$\mathrm{Bu}$ yöntemle sentezlenen bileşikler kaynama noktalan ve sentez verimleri ile birlikte Tablo: l'de verilmektedir.

Tablo 1. Sentezlenen dialkilaminoetanol bileşikleri.

\begin{tabular}{|l|c|c|}
\hline \multicolumn{1}{|c|}{ Bileşik } & Kaynama Noktası & Sentez Verimi \\
\hline 2-Dimetilaminoetanol & $134.3^{\circ} \mathrm{C}$ & $\% 60.0$ \\
2-Dietilaminoetanol & $158.2^{\circ} \mathrm{C}$ & $\% 63.0$ \\
2-Di-n-propilaminoetanol & $194.6^{\circ} \mathrm{C}$ & $\% 62.4$ \\
2-Diizopropilaminoetanol & $188.1^{\circ} \mathrm{C}$ & $\% 62.0$ \\
2-Di-n-butilaminoetanol & $215.1^{\circ} \mathrm{C}$ & $\% 67.0$ \\
\hline
\end{tabular}

\section{2-Dialkilaminoetil klorür Hidroklorür Bilessiklerinin Sen-} tezi $(14,18)$

2 lt lik 3 boyunlu bir balona $750 \mathrm{ml}$ benzende çözülmüş $1 \mathrm{~mol}$ dialkilaminoetanol konuldu. Balonun boyunlarindan birine damlatma hunisi, birine geri çeviren soğutucu, diğerine ise mekanik karıştırıcı takıldı. Balon içeriği buz banyosu üzerinde soğutulurken damlatma hunisi aracılığı ile 1.1 mol tiyonil klorür 1 saat içinde damla damla ilave edildi. Tiyonil klorürün tamamının ilavesinden sonra balon buz banyosu üzerinden alındı ve balon ısıtıcısı üzerinde 4 saat karıştırılarak 1sıtıldı. Bu süre sonunda balon içeriği sicakken 2 lt lik bir behere aktarıldı. Soğutma sonucu çöken bileşikler süzülerek alındı, kurutuldu ve aktif kömürden geçirilerek metanolden tekrar kristallendirildi.

Bu yöntemle elde edilen bileşikler Tablo: 2 de ergime noktaları ve sentez verimleri ile birlikte gösterilmektedir.

\section{Benzoik Asit Esteri Lokal Anestezik Bileşiklerin Genel Sentezi (19)}

Eşit moleküllerde (0.013-0.030 mol) asit ve dialkilaminoetil klorür hidroklorür, $200 \mathrm{ml}$ lik bir balon içinde $75 \mathrm{ml}$ etil asetat ve 5 
Tablo 2. Sentezlenen dialkilaminoetil klorür hidroklorür bileşikleri.

\begin{tabular}{|lc|c|}
\hline \multicolumn{1}{|c|}{ Bileşik } & Kaynama Noktası & Sentez Verimi \\
\hline 2-Dimetilaminoetil klorür HC1 & $209.2^{\circ} \mathrm{C}$ & $\% 87.0$ \\
2-Dietilaminoetil klorür HCl & $209.4^{\circ} \mathrm{C}$ & $\%$ \\
2-Di-n-propilaminoetil klorür HCI & $121.5^{\circ} \mathrm{C}$ & $\% 79.0$ \\
2-Diizopropilaminoetil klorür HCI & $132.9^{\circ} \mathrm{C}$ & $\% 81.3$ \\
2-Di-n-butilaminoeti klorür HCI & $82.3^{\circ} \mathrm{C}$ & $\% 76.8$ \\
\hline
\end{tabular}

ml metanol içinde çözüldü. Çözeltiye kullanılan asit ve dialkilaminoetil klorür hidroklorürün 2 katı molekül ağırlığında trietilamin ilave edildi. Bu esnada, derhal trietilamin hidroklorür çöküşü başladı. Karışım, geri çeviren soğutucu altında, yă̆ banyosu ve manyetik karıştırıcı üzerinde $120-130^{\circ} \mathrm{C}$ de $38-50$ saat karıştırılarak tutuldu. Bu süre sonunda, balon içeriği soğutuldu, çöken trietilamin hidroklorür süzülerek ortamdan uzaklaştırıldı. Süzüntü sırasıyla 3 kez 50 şer $\mathrm{ml}$ distile su, $1 \mathrm{kez} 50 \mathrm{ml} \% 10$ luk sodyum bikarbonat çözeltisi ve yine $2 \mathrm{kez} 50$ şer $\mathrm{ml}$ distile su ile çalkalandı ve sulu tabakalar atıldı. Böylece ortamda kalabilecek sentez başlangıç bileşikleri tamamen uzaklaştırıldı. Etil asetatlı tabaka susuz sodyum sülfat üzerinden geçirilerek kurutuldu, etil asetatın fazlası uçuruldu, izopropil alkol ile seyreltildi ve ortam asit olana kadar damla damla derişik hidroklorik asit çözeltisi kondu. Ortama eter ilavesiyle çöken bileşikler süzülerek alındı, kurutuldu ve izopropil alkolden tekrar kristallendirilip vakum etüvünde kurutuldu.

Sentezlenen benzoik asit esteri bileşikler Tablo: 3 de toplu halde gösterilmektedir. 40 bileşiğin 13 ü ilk kez bu çalışmada yapılmış, diğerlerinin ise literatür no. lan tabloda gösterilmiştir. Sentezleri daha önce yapılan bileşiklerin verileri literatürdekilere uymakla beraber yapıları, aletsel analiz yöntemleri ile bir kez daha kanıtlanmıştır. İlk kez bu çalışmada sentezlenen bileşiklerin yapı açıklamaları ise Bulgular kısmında ayrı ayrı verilmiştir.

\section{Sentezlenen Bileşiklerin İncelenmesi}

1) UV Spektrumları: Sentez edilen tüm bileşiklerin UV spektrumları spektral saflıkta metanol içinde, 2 X $10^{-5}$ M çözeltilerinde alınmış ve 190-400 $\mathrm{nm}$ arasında tarama yapılmıştır. Spektrumlarda görülen maksimumlar, benzen halkası üzerindeki gruplara göre değişmekte, yan zincirdeki alkil değişikliklerinden ise etkilenmemektedir. 
Tablo 3. Sentezlenen benzoik asit esteri lokal anestezik bileşikler.

\begin{tabular}{|c|c|c|c|c|c|c|}
\hline \multirow{2}{*}{$\mathrm{R}_{1}$} & \multirow{2}{*}{$\mathrm{R}_{2}$} & \multicolumn{5}{|c|}{$\mathrm{R}_{3}$ (lit.) } \\
\hline & & Me & Et & $n$-Pr & $t-\operatorname{Pr}$ & $\boldsymbol{n}-B u$ \\
\hline $\mathbf{H}$ & $\mathbf{H}$ & $\begin{array}{c}1 \\
{[20-23]}\end{array}$ & $\begin{array}{c}2 \\
(20,22,24)\end{array}$ & $\begin{array}{r}3 \\
(20,22)\end{array}$ & $\begin{array}{r}4 \\
(20,22)\end{array}$ & $\begin{array}{c}5 \\
(20,22,24]\end{array}$ \\
\hline $\mathrm{OC} \mathrm{H}_{3}$ & $\mathbf{H}$ & $\begin{array}{c}6 \\
(21,23,25)\end{array}$ & $\begin{array}{c}7 \\
(25-29)\end{array}$ & $8^{*}$ & $9^{*}$ & 10 * \\
\hline $\mathrm{NO}_{2}$ & $\mathbf{H}$ & $\begin{array}{c}11 \\
(21,30,31)\end{array}$ & $\begin{array}{c}12 \\
(32,34)\end{array}$ & $\begin{array}{c}13 \\
(30,31,33)\end{array}$ & $\begin{array}{c}14 \\
{[30,31,33)}\end{array}$ & $\begin{array}{c}15 \\
(30,31,33)\end{array}$ \\
\hline $\mathrm{NH}_{2}$ & $\mathbf{H}$ & $\begin{array}{c}16 \\
(30,31,35)\end{array}$ & $\begin{array}{c}17 \\
(30,32.33 \\
36,3)\end{array}$ & $\begin{array}{c}18 \\
(30,31,33)\end{array}$ & $\begin{array}{c}19 \\
(30.31,33.38)\end{array}$ & $\begin{array}{c}20 \\
(30,31,33)\end{array}$ \\
\hline $\mathbf{H}$ & $\mathrm{CH}_{3}$ & ${ }^{21}$ & $\begin{array}{r}22 \\
(27,39)\end{array}$ & 23 & & $25 *$ \\
\hline $\mathbf{H}$ & $\mathrm{OC} \mathrm{H}_{3}$ & $\begin{array}{c}2 E \\
(21,23)\end{array}$ & $\begin{array}{c}27 \\
(28,29,39)\end{array}$ & 28 & $29 *$ & 30 \\
\hline $\mathbf{H}$ & $\mathrm{NO}_{2}$ & 31 * & $\begin{array}{r}32 \\
(40,41)\end{array}$ & 33 & $34^{\circ}$ & $35 *$ \\
\hline $\mathbf{H}$ & $\mathrm{N} \mathrm{H}_{2}$ & $\begin{array}{r}36 \\
(42)^{36}\end{array}$ & $\begin{array}{r}37 \\
(40,42)\end{array}$ & $(42)^{38}$ & $(42)^{39}$ & $\begin{array}{r}40 \\
(42)^{4}\end{array}$ \\
\hline
\end{tabular}

* ilk kez bu çalışmada sentezi erimiştir.

2) İR Spektrumları: Sentez edilen tüm bileşiklerin İ spektrumları potasyum bromür pelletleri şeklinde hazırlanarak alınmıştır. Yapı olarak birbirine benzeyen bileşiklerde, aşağıda verilen bantlar ortakdir:

$$
\begin{aligned}
& \begin{array}{l}
3100-3000 \mathrm{~cm}^{-1} \\
2980-2880 \mathrm{c} \mathrm{m}^{-1}
\end{array} \quad \mathrm{C}-\mathrm{H} \text { gerilimleri } \\
& 2600-2460 \mathrm{c} \mathrm{m}^{-1} \quad \mathrm{~N}^{+}-\mathrm{H} \text { gerilimleri }
\end{aligned}
$$




$$
\begin{aligned}
& \text { 1740-1690 } \mathrm{c} \mathrm{m}^{-1} \mathrm{C}=0 \text { gerilimleri } \\
& \text { 1610-1500 } \mathrm{c} \mathrm{m}^{-1} \quad \mathrm{C}=\mathrm{C} \text { gerilimleri } \\
& \text { 1480-1450 } \mathrm{c} \mathrm{m}^{-1} \quad \mathrm{C}-\mathrm{H} \text { eğilimleri } \\
& \text { 1400-1370 } \mathrm{c} \mathrm{m}^{-1} \text { metil } \mathrm{C}-\mathrm{H} \text { eğilimleri } \\
& \text { 1300-1010 } \mathrm{c} \mathrm{m}^{-1} \quad \mathrm{C}-\mathrm{O} \text { eğilimleri } \\
& 850-730 \mathrm{~cm}^{-1} \quad \mathrm{C}-\mathrm{H} \text { plan dişı eğilimleri }
\end{aligned}
$$

Ortak olan bu bantların dışında, benzen halkası üzerinde alkil ve alkoksil grubu taşıyan bileşiklerde özel bir bant görülmemektedir. Nitro grubu taşıyanlarda asimetrik nitro gerilim bantları 1550-1540 $\mathrm{cm}^{-1}$, simetrik nitro gerilimleri 1380-1360 $\mathrm{cm}^{-1}$, amin grubu taş1yanlarda ise $\mathrm{N}-\mathrm{H}$ gerilim bantları 3500-3200 $\mathrm{cm}^{-1}$ ve $\mathrm{N}-\mathrm{H}$ eğilimleri 1645-1640 $\mathrm{c} \mathrm{m}^{-1}$ de bulunmaktadir.

Yukarıda sayılan bantlar tüm bileşikler için geçerli olduğundan Bulgular kısmında, her bileşiğin İR spektrumunun ayrı ayrı çözümlenmesine gerek duyulmamıştır.

3) NMR Spektrumları: Sentezlenen bileşiklerin NM R spektrumları, tuzların çözünebileceği bir çözücü olan dimetilsulfoksit-d ${ }_{6}$ içinde alınmıştır. Bu çalışmada ilk kez sentezlenen bileşiklerin N M R spektrumları, Bulgular kısmında ayrı ayrı verilmektedir.

4) Kütle Spektrumları: Sentez edilen bileşiklerin tümünün kütle spektrumu alınmıştır. Spektrumlarda parçalanma yan zincirdeki amin grubu üzerindeki alkillerden başlamakta ve ara zincirin tam ortasından meydana gelen kopuşla ana pik görülmektedir. Bu bölünme sonucu oluşan parçalardan biri son derece dayanıksızdır ve derhal parçalanmaktadır. Ana piki oluşturan parça ise daha dayanıklıdır ve daha yavaş parçalanmaktadır. Dayanıksız olan parça bir metilen grubu ve buna bağlı olarak ester oksijenini kaybederek (formaldehit kopuşu) karbonil fonksiyonunu radikal olarak bırakmaktadır. Aromatik halkanın parçalanması sonucu düşük değerde iyonlar oluşmaktadır, ancak bu parçalar yan zincirlerin parçalanma ürünleri ile karıştı̆̆ından fikir verici niteliğini kaybetmektedir.

Bu çalışmada ilk kez sentezlenen bileşiklerin kütle spektrumları Bulgular kısmında ayrı ayrı incelenmiştir. 


\section{BULGULAR}

1. 2-Di-n-propilaminoetil p-metoksibenzoat Hidroklor ür (Bileşik: 8)

Genel yönteme göre yapilan sentezde $2.28 \mathrm{~g}$ p-metoksibenzoik asit, $3 \mathrm{~g}$ di-n-propilaminoetil klorür hidroklorür ve $3.03 \mathrm{~g}$ trietilamin kullanıldı. Sentez sonunda $4.03 \mathrm{~g}$ saf bileşik elde edildi. (Verim: \% $85.16)$

\section{E. N.: $122.9^{\circ} \mathrm{C}$} $17950)$

UV Spektrumu : $\lambda$ maks. $207(\varepsilon=5800)$ ve $261 \mathrm{~nm}(\varepsilon=$

NM R Spektrumu : $\delta$ ppm. 0.95 (propil gruplarının metil protonları, 6 H, t), 1.45-2.20 (propil gruplarının 2. konumlarındaki metilen protonlar, 4H, m), 3.00-3.90 (azot atomuna bağlı metilen protonları, $6 \mathrm{H}, \mathrm{m}$ ), 4.03 (benzen halkasının para konumundaki metoksil protonları, $3 \mathrm{H}, \mathrm{s}$ ), 4.88 (oksijen atomuna bağlı metilen protonları, $2 \mathrm{H}, \mathrm{t}$ ), 7.40 (benzen halkasinın o ve o' protonları, 2H, d), 8.38 (benzen halkasının $\mathrm{m}$ ve $\mathrm{m}^{\prime}$ protonları, $2 \mathrm{H}$, d)

Kütle Spektrumu:

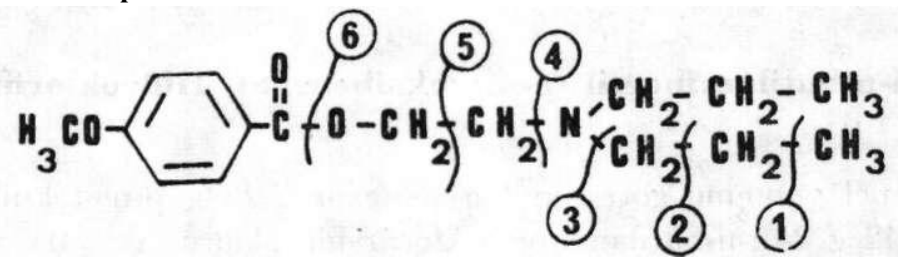

M+279 (Moleküler iyon, \% 2, 85)
1) $\mathrm{m} / \mathrm{e} 264\left(\mathrm{M}^{+}-15, \%\right.$ 42.85)
2) $\mathrm{m} / \mathrm{e} \quad 250 \quad\left(\mathrm{M}^{+}-29, \%\right.$ 3.33)
3) $\mathrm{m} / \mathrm{e} 236\left(\mathrm{~m}^{+}-43, \% 34.28\right)$
4) $\mathrm{m} / \mathrm{e} 170\left(\mathrm{M}^{+}-100, \% 73.33\right)$
5) $\mathrm{m} / \mathrm{e} 114$ (Ana pik, \% 100)
6) $\mathrm{m} / \mathrm{e} 135(\mathrm{M}+-144, \%$ 73.33)

2. 2-Diizopropilaminoetil p-metoksibenzoat Hidroklorür (Bileşik: 9)

Genel Yönteme göre yapılan sentezde 2.28 g p-metoksibenzoik asit, $3.00 \mathrm{~g}$ 2-diizopropilaminoetil klorür hidroklorür ve $3.03 \mathrm{~g}$ trietilamin kullanıldı. Sentez sonunda $4.15 \mathrm{~g}$ saf bileşik elde edildi. (Verim: 87.69)

E. N.: $141.9^{\circ} \mathrm{C}$ 
UV Spektrumu: $\lambda$ maks. $207(\varepsilon=5500)$ ve $261 \mathrm{~nm}(\varepsilon=11450)$

N M R Spektrumu : $\delta$ ppm. 1.43 (izopropil grubunun metil protonları, 12H, dd), 3.40-4.00 (azot atomuna bağlı metilen ve metin protonları, 4H, m), 4.05 (benzen halkasının para konumundaki metoksil protonları, $3 \mathrm{H}, \mathrm{s}$ ), 4.87 (oksijen atomuna bağlı metilen protonları, 2H, t), 7.43 (benzen halkasinın o ve o' protonları, 2 H, d), 8.40 (benzen halkasının $\mathrm{m}$ ve $\mathrm{m}^{\prime}$ protonları, $2 \mathrm{H}$, d)

\section{Kütle Spektrumu:}

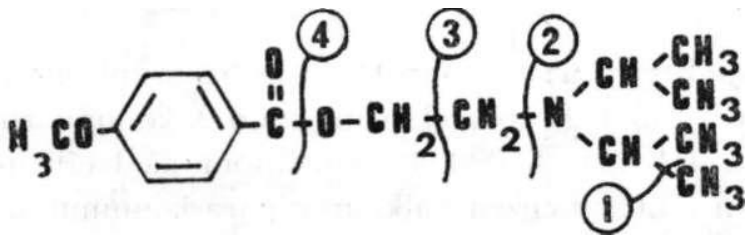

M+ 279 (Moleküler iyon, \% 4. 0)
1) $\mathrm{m} / \mathrm{e} 264(\mathrm{M}+-15, \% 21.0)$
2) $\mathrm{m} / \mathrm{e} \quad 179(\mathrm{M}+-100, \%$ 46.0)
3) $\mathrm{m} / \mathrm{e} 114$ (Ana pik, \% 100)
4) $\mathrm{m} / \mathrm{e} \quad 135(\mathrm{M}+-144, \%$ 80.0)

3. 2-Di-n-butilaminoetil p-metoksibenzoat Hidroklorür (Bileşik: 10)

Genel yönteme göre yapılan sentezde $2.28 \mathrm{~g}$ p-metoksibenzoik asit, 3.42 g 2-di-n-butilaminoetil klorür hidroklorür ve 3.03 g trietilamin kullanıldı. Sentez sonunda 4.23 g saf bileşik elde edildi. (Verim: $\%$ 82.10)

E.N.: $112.0^{\circ} \mathrm{C}$

UV Spektrumu: $\lambda$ maks. $207(\varepsilon=9850)$ ve $261(\varepsilon=14150)$

NMR Spektrumu: $\delta$ ppm. 0.92 (butil gruplarinın metil protonlar1, $6 \mathrm{H}, \mathrm{t}$ ), $1.10-2.10$ (butil gruplarının 2 ve 3 no.lu metilen protonları, $8 \mathrm{H}, \mathrm{m}$ ), 3.00-3.90 (azot atomuna bağlı metilen protonları, $6 \mathrm{H}, \mathrm{m}$ ), 4.00 (benzen halkasının para konumundaki metoksil protonları, 3H, s), 4.87 (oksijen atomuna bağlı metilen protonları, $2 \mathrm{H}, \mathrm{t}$ ), 7.37 (benzen halkasının o ve o' protonları, $2 \mathrm{H}, \mathrm{d}$ ), 8.33 (benzen halkasının $\mathrm{m}$ ve $\mathrm{m}^{\prime}$ protonları, $2 \mathrm{H}$, d) 
Kütle Spektrumu :

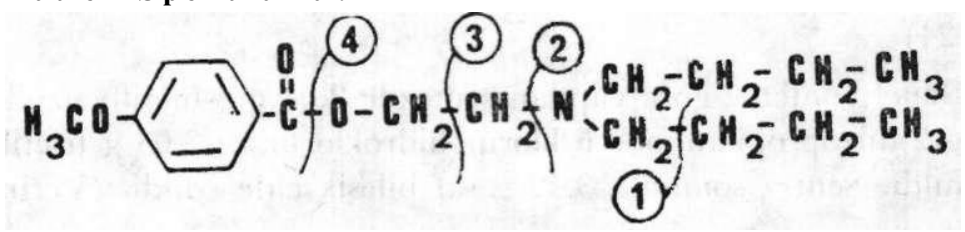

M $^{+} 307$ (Moleküler iyon, \% 7. 76)

1) $\mathrm{m} / \mathrm{e} 264\left(\mathrm{M}^{+}-43, \% 47.76\right)$

2) $\mathrm{m} / \mathrm{c} 179(\mathrm{M}+-128, \% 52.24)$

3) $\mathrm{m} / \mathrm{e} 142$ (Ana pik, \% 100)

4) $\mathrm{m} / \mathrm{e} 135(\mathrm{M}+-172, \%$ 89.11)

4. 2-Di-n-propilaminoetil o-metilbenzoat Hidroklor ür Bileşik: 23)

Genel yönteme göre yapılan sentezde 2.04 g o-metilbenzoik asit, 3.00 g 2-di-n-propilaminoetil klorür hidroklorür ve 3.03 g trietilamin kullanıldı. Sentez sonunda $3.65 \mathrm{~g}$ saf bileşik elde edildi. (Verim :\% 81.29)

E. N.: $149.0^{\circ} \mathrm{C}$

UV Spektrumu: $\lambda$ maks. $205(\varepsilon=16000), 235(\varepsilon=8500)$ ve $281 \mathrm{~nm}(\varepsilon=3500)$

NM R Spektrumu: $\delta$ ppm. 0.97 (propil gruplarının metil protonları, 6H, t), 1.33-2.10 (propil gruplarının 2. konumundaki metilen protonları, $4 \mathrm{H}, \mathrm{m}$ ), 2.55 (benzen halkasının orto konumundaki metil protonları, 3H, s), 2.80-4.05 (azot atomuna bağl1 metilen protonlar1, $6 \mathrm{H}, \mathrm{m}$ ), 4.80 (oksijen atomuna bağlı metilen protonları, $2 \mathrm{H}, \mathrm{t}$ ), 7.63 (benzen halkasinın $\mathrm{m}$, m' ve p protonları, $3 \mathrm{H}, \mathrm{m}$ ), 8.10 (benzen halkasının o' protonu, $1 \mathrm{H}, \mathrm{d})$

Kütle Spektrumu :

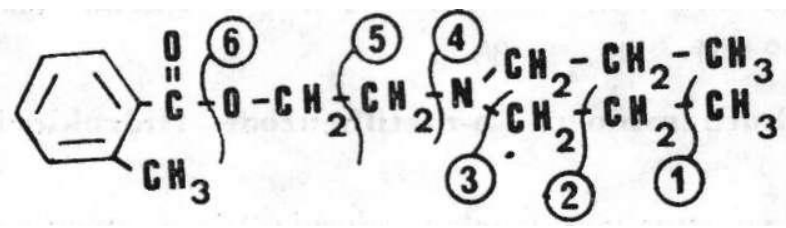

M $^{+} 263$ (Moleküler iyon, \% 11.94)
1) $\mathrm{m} / \mathrm{e} 248\left(\mathrm{M}^{+}-15, \% 17.91\right)$
2) $\mathrm{m} / \mathrm{e} 234\left(\mathrm{M}^{+}-29, \% 4.93\right)$
3) $\mathrm{m} / \mathrm{e} 220\left(\mathrm{M}^{+}-43, \% 41.79\right)$
4) $\mathrm{m} / \mathrm{e} 163\left(\mathrm{M}^{+}-100, \%\right.$ 61.19)
5) $\mathrm{m} / \mathrm{e} 114$ (Ana pik, \% 100)
6) $\mathrm{m} / \mathrm{e} 119\left(\mathrm{M}^{+}-144, \% 97.01\right)$ 
5. 2-Diizopropilaminoetil o-metilbenzoat Hidroklorür (Bileşik: 24)

Genel yönteme göre yapılan sentezde $2.04 \mathrm{~g}$ o-metilbenzoik asit, 3.00 g 2-diizopropilaminoetil klorür hidroklorür ve 3.03 g trietilamin kullanıldı. Sentez sonunda 3.52 g saf bileşik elde edildi. (Verim: \% 78.39)

\section{E. N.: $137.2^{\circ} \mathrm{C}$}

UV Spektrumu: $\lambda$ maks. $205(\varepsilon=16500), 235(\varepsilon=8500)$ ve $281 \mathrm{~nm}(\varepsilon=3500)$

NMR Spektrumu : $\delta$ ppm. 1.43 (izopropil gruplarının metil protonları, $12 \mathrm{H}, \mathrm{dd}$ ), 2.67 (benzen halkasının orto konumundaki metil protonları, $3 \mathrm{H}, \mathrm{s}$ ), 3.40-4.20 (azot atomuna bağlı metilen ve metin protonları, $4 \mathrm{H}, \mathrm{m}$ ), 4.80 (oksijen atomuna bağlı metilen protonları, $2 \mathrm{H}, \mathrm{t}$ ), 7.70 (benzen halkasının $\mathrm{m}, \mathrm{m}^{\prime}$ ve p protonları, $3 \mathrm{H}$ $\mathrm{m}$ ), 8.15 (benzen halkasının o' protonu, $1 \mathrm{H}, \mathrm{d}$ )

\section{Kütle Spektrumu:}

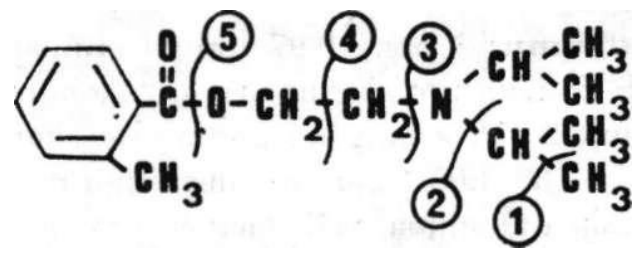

M $^{+} 263$ (Moleküler iyon, \% 6. 42)

1) $\mathrm{m} / \mathrm{e} 248\left(\mathrm{M}^{+}-15, \%\right.$ 14.92 $) \quad$ 2) $\mathrm{m} / \mathrm{e} 220 \quad\left(\mathrm{M}^{+}-43, \%\right.$ 3.73)

3) $\mathrm{m} / \mathrm{c} 163\left(\mathrm{M}^{+}-100, \% 37.31\right)$ 4) $\mathrm{m} / \mathrm{e} 114$ (Ana pik, \% 100)

5) $\mathrm{m} / \mathrm{e} 119\left(\mathrm{M}^{+}-144, \% 88.11\right)$

6. 2-Di-n-butilaminoetil o-metilbenzoat Hidroklorür (Bileşik: 25)

Genel yönteme göre yapılan sentezde $2.04 \mathrm{~g}$ o-metilbenzoik asit, $3.42 \mathrm{~g}$ di-n-butilaminoetil klorür hidroklorür ve $3.03 \mathrm{~g}$ trietilamin kullanıldı. Sentez sonunda 3.80 g saf bileşik elde edildi. (Verim: \% 77.39)

E.N.: $121.8^{\circ} \mathrm{C}$ 
UV Spektrumu: $\lambda$ maks. $205(\varepsilon=16000), 235(\varepsilon=8500)$ ve $281 \mathrm{~nm}(\varepsilon=3500)$

NMR Spektrumu: $\delta$ ppm. 0.83 (Butil gruplarının metil protonlar1, $6 \mathrm{H}, \mathrm{t}$ ), 1.00-2.00 (butil gruplarının 2 ve 3 no.lu metilen protonlar1, $8 \mathrm{H}, \mathrm{m}$ ), 2.56 (benzen halkasının orto konumundaki metil protonları, $3 \mathrm{H}, \mathrm{s}$ ), 2.80-3.80 (azot atomuna bağl1 metilen protonları, $6 \mathrm{H}, \mathrm{m}$ ), 4.80 (oksijen atomuna bağlı metilen protonlar $, 2 \mathrm{H}, \mathrm{t}$ ), 7.65 (benzen halkasinın $\mathrm{m}$, $\mathrm{m}^{\prime}$ ve p protonları, $3 \mathrm{H}, \mathrm{m}$ ), 8.20 (benzen halkasinın o' protonu, $1 \mathrm{H}, \mathrm{d})$

\section{Kütle Spektrumu:}

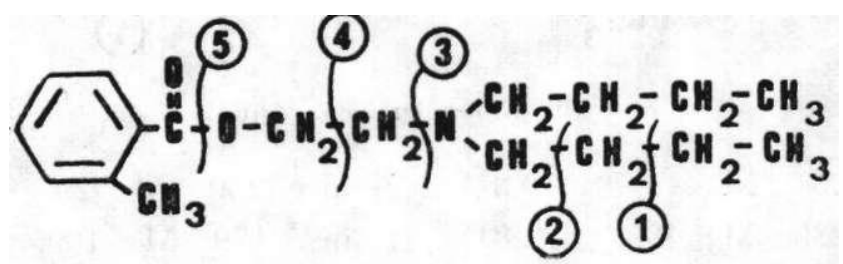

M $^{+} 291$ (Moleküler iyon, \% 6. 62)

1) $\mathrm{m} / \mathrm{e} 262\left(\mathrm{M}^{+}-29, \% 5.08\right)$

3) $\mathrm{m} / \mathrm{e} 163\left(\mathrm{M}^{+}-128, \% 36.15\right)$

5) $\mathrm{m} / \mathrm{e} 119\left(\mathrm{M}^{+}-172, \% 83.23\right)$
2) $\mathrm{m} / \mathrm{e} 248\left(\mathrm{M}^{+}-43, \% 33.85\right)$

4) $\mathrm{m} / \mathrm{e} 142$ (Ana pik, \% 100)

7. 2-Di-n-propilaminoetil o-metoksibenzoat Hidroklor ür (Bileşik: 28)

Genel yönteme göre yapılan sentezde 2.28 g o-metoksibenzoik asit, $3.00 \mathrm{~g} 2$-di-n-propilaminoetil klorür hidroklorür ve $3.03 \mathrm{~g}$ trietilamin kullanıldı. Sentez sonunda 3.73 g saf bileşik elde edildi. (Verim: $\%$ 78.82)

E. N.: $131.3^{\circ} \mathrm{C}$

UV S pektrumu : $\lambda$ maks. $209(\varepsilon=16500), 239(\varepsilon=5500)$ ve $299 \mathrm{~nm}(\varepsilon=3500)$

NMR Spektrumu: $\delta$ ppm. 1.03 (propil gruplarinin metil protonları, 6H, t), 1.60-2.40 (propil gruplarının 2 no.lu metilen protonları, 4H, m), 3.00-4.00 (azot atomuna bağlı metilen protonları, $6 \mathrm{H}$, 
m), 4.08 (benzen halkasının orto konumundaki metoksil protonları, $3 \mathrm{H}, \mathrm{s}$ ), 4.97 (oksijen atomuna bağl1 metilen protonları, $2 \mathrm{H}, \mathrm{t}$ ), 7.20 7.60 (benzen halkasının $\mathrm{m}$ ve $\mathrm{m}^{\prime}$ protonları, $2 \mathrm{H}, \mathrm{m}$ ), 7.70-8.00 (benzen halkasının p protonu, $1 \mathrm{H}, \mathrm{m}$ ), 8.00-8.30 (benzen halkasinın o' protonu, $1 \mathrm{H}, \mathrm{dd})$

\section{Kütle Spektrumu:}

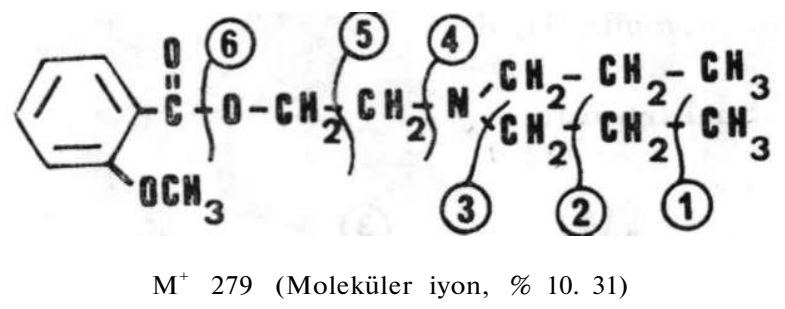
1) $\mathrm{m} / \mathrm{e} 264\left(\mathrm{M}^{+}-15, \% 10.31\right)$
2) $\mathrm{m} / \mathrm{e} \quad 250 \quad\left(\mathrm{M}^{+}-29, \% 61.90\right)$
3) $\mathrm{m} / \mathrm{e} 236\left(\mathrm{M}^{+}-43, \% 23.81\right)$
4) $\mathrm{m} / \mathrm{e} 179\left(\mathrm{M}^{+}-100, \% 73.01\right)$
5) $\mathrm{m} / \mathrm{e} 114$ (Ana pik, \% 100)
6) $\mathrm{m} / \mathrm{e} 135\left(\mathrm{M}^{+}-144, \% 90.48\right)$

8. 2-Diizopropilaminoetil o-metoksibenzoat Hidroklor ür (Bileşik: 29)

Genel yönteme göre yapılan sentezde $2.28 \mathrm{~g}$ o-metoksibenzoik asit, $3.00 \mathrm{~g}$ 2-diizopropilaminoetil klorür hidroklorür ve $3.03 \mathrm{~g}$ trietilamin kullanıldı. Sentez sonunda $3.71 \mathrm{~g}$ saf bileşik elde edildi. (Verim: \% 78.3

E.N.: $129.5^{\circ} \mathrm{C}$

UV Spektrumu: $\lambda$ maks. $209(\varepsilon=17000), 239(\varepsilon=6000)$ ve $299 \mathrm{~nm}(\varepsilon=350)$.

NMR Spektrumu: $\delta$ ppm. 1.37 (izopropil gruplarının metil protonları, $12 \mathrm{H} \mathrm{dd}$ ), 3.33-3.80 (azot atomuna bağlı metilen ve metin protonları, $4 \mathrm{H}, \mathrm{m}$ ), 3.93 (benzen halkasının orto konumundaki metoksil protonları, $3 \mathrm{H}, \mathrm{s}$ ), 4.80 (oksijen atomuna bağlı metilen protonlar1, 2H, t), 7.10-7.50 (benzen halkasinın $\mathrm{m}$ ve $\mathrm{m}^{\prime}$ protonlar1, $2 \mathrm{H}$, $\mathrm{m}$ ), 7.50-7.80 (benzen halkasının p protonu, 1H, m), 7.90-8.20 (benzen halkasının o' protonu, $1 \mathrm{H}, \mathrm{dd}$ ) 
Kütle Spektrumu:

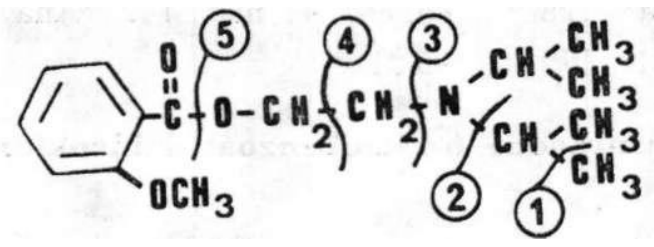

M+279 (Moleküler iyon, \% 23. 43)
1) $\mathrm{m} / \mathrm{e} 264\left(\mathrm{M}^{+}-15, \% 5.62\right)$
2) $\mathrm{m} / \mathrm{e} 236\left(\mathrm{M}^{+}-43, \%\right.$ 11.71)
3) $\mathrm{m} / \mathrm{e} 179\left(\mathrm{M}^{+}-100, \% 76.56\right)$
4) $\mathrm{m} / \mathrm{e} 114$ (Ana pik, \% 100)
5) $\mathrm{m} / \mathrm{e} 135\left(\mathrm{M}^{+}-144, \% 92.18\right)$

9. 2-Di-n-butilaminoetil o-metoksibenzoat Hidroklorür (Bileşik: 30 )

Genel yönteme göre yapılan sentezde $2.28 \mathrm{~g}$ o-metoksibenzoik asit, 3.42 g 2-di-n-butilaminoetil klorür hidroklorür ve 3.03 g trietilamin kullanıldı. Sentez sonunda $3.97 \mathrm{~g}$ saf bileşik elde edildi. (Verim: $\%$ 77.0)

\section{E. N.: $91.9^{\circ} \mathrm{C}$}

UV Spektrumu: $\lambda$ maks. $209(\varepsilon=16500), 239(\varepsilon=6500)$ ve $299 \mathrm{~nm}(\varepsilon=3000)$.

N M R Spektrumu : $\delta$ p pm. 0.97 (butil gruplarının metil protonları, 6H, t), 1.10-2.10 (butil gruplarının 2 ve 3 no.lu metilen protonları, $8 \mathrm{H}, \mathrm{m}$ ), 3.00-3.90 (azot atomuna bağlı metilen protonları, $6 \mathrm{H}$, $\mathrm{m}$ ), 4.00 (benzen halkasının örto konumundaki metoksil protonları, $3 \mathrm{H}, \mathrm{s}$ ), 4.87 (oksijen atomuna bağlı metilen protonları, $2 \mathrm{H}, \mathrm{t}$ ), 7.20 7.57 (benzen halkasinın $\mathrm{m}$ ve $\mathrm{m}$ ' protonlar $1,2 \mathrm{H}, \mathrm{m}$ ), 7.80-8.00 (benzen halkasının p protonu, 1H, m), 8.00-8.30 (benzen halkasinın o' protonu, $1 \mathrm{H}, \mathrm{dd})$

Kütle Spektrumu :

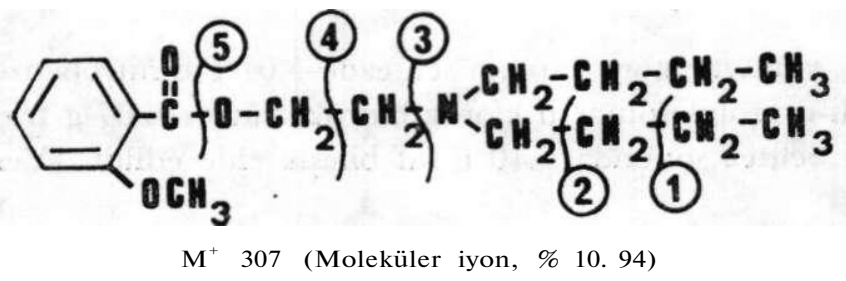


1) $\mathrm{m} / \mathrm{e} 278\left(\mathrm{M}^{+}-29, \% 10.94\right)$

2) $\mathrm{m} / \mathrm{e} 264\left(\mathrm{M}^{+}-43, \% 80.47\right)$

3) $\mathrm{m} / \mathrm{e} 179\left(\mathrm{M}^{+}-128, \%\right.$ 83.59)

4) $\mathrm{m} / \mathrm{e} 142$ (Ana pik, \% 100)

5) $\mathrm{m} / \mathrm{e} 135\left(\mathrm{M}^{+}-172, \% 95.31\right)$

10. 2-Dimetilaminoetil o-nitrobenzoat Hidroklorür (Bileşik: 31)

Genel yönteme göre yapılan sentezde $5.01 \mathrm{~g}$ o-nitrobenzoik asit, $4.32 \mathrm{~g}$ 2-dimetilaminoetil klorür hidroklorür ve $6.07 \mathrm{~g}$ trietilamin kullanıldı. Sentez sonunda $6.15 \mathrm{~g}$ saf bileşik elde edildi. (Verim: \% $74.65)$

E. N.: $155.5^{\circ} \mathrm{C}$

UV Spektrumu: $\lambda$ maks. $212(\varepsilon=6650)$ ve $260 \mathrm{~nm}(\varepsilon=$ 1250)

NM R Spektrumu : $\delta$ ppm. 2.95 (azot atomuna bağlı metil protonları, $6 \mathrm{H}, \mathrm{s}$ ), 3.60 (azot atomuna bağl1 metilen protonları, $2 \mathrm{H}, \mathrm{t}$ ), 4.87 (oksijen atomuna bağlı metilen protonları, $2 \mathrm{H}, \mathrm{t}$ ), 8.34 (benzen halkasının tüm protonları, $4 \mathrm{H}, \mathrm{m})$

Kütle Spektrumu:

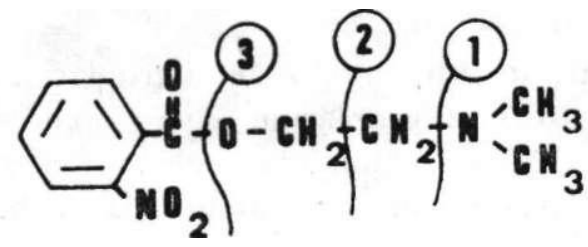

$\mathrm{M}^{+} 238$ (Moldküler iyon, \% 70. 77)

1) $\mathrm{m} / \mathrm{e} 194\left(\mathrm{M}^{+}-44, \% 53.35\right) \quad$ 2) $\mathrm{m} / \mathrm{e} 58$ (Ana pik, \% 100)

3) $\mathrm{m} / \mathrm{e} 150\left(\mathrm{M}^{+}-88, \%\right.$ 92.30)

11. 2-Di-n-propilaminoetil o-nitrobenzoat Hidroklor ür (Bileşik: 33)

Genel yönteme göre yapılan sentezde $5.01 \mathrm{~g}$ o-nitrobenzoik asit, 6.00 g 2-di-n-propilaminoetil klorür hidroklorür ve 6.07 g trietilamin kullanıldı. Sentez sonunda $7.10 \mathrm{~g}$ saf bileşik elde edildi. (Verim: \% $71.61)$

E. N.: $112.5^{\circ} \mathrm{C}$ 
UV Spektrumu: $\lambda$ maks. $212(\varepsilon=8650)$ ve $260 \mathrm{~nm}(\varepsilon=500)$

NMR Spektrumu: $\delta$ ppm. 0.93 (propil gruplarının metil protonlari, $6 \mathrm{H}, \mathrm{t}$ ), 1.50-2.20 (propil gruplarının 2 no.lu metilen protonları, 4H, m), 3.00-4.00 (azot atomuna bağlı metilen protonları, 6 H, m), 4.97 (oksijen atomuna bağlı metilen protonları, $2 \mathrm{H}, \mathrm{t}$ ), 8.40 (benzen halkasının tüm protonları, $4 \mathrm{H}, \mathrm{m}$ ).

\section{Kütle Spektrumu:}

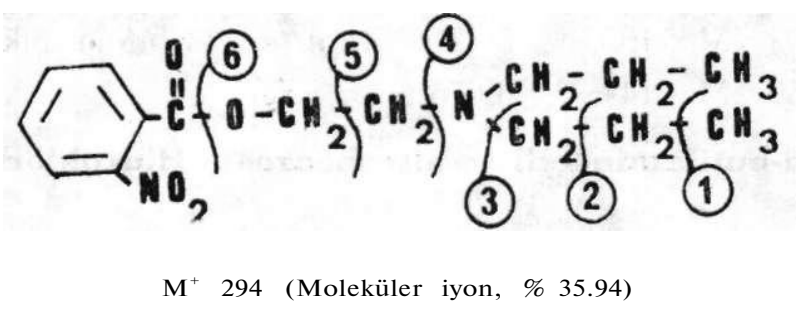
1) $\mathrm{m} / \mathrm{e} 279\left(\mathrm{M}^{+}-15, \% 31.25\right)$
2) $\mathrm{m} / \mathrm{e} 265\left(\mathrm{M}^{+}-29, \% 14.84\right)$
3) $\mathrm{m} / \mathrm{e} 251\left(\mathrm{M}^{+}-43, \% 20.31\right)$
4) $\mathrm{m} / \mathrm{e} 194\left(\mathrm{M}^{+}-100, \% 92.30\right)$
5) $\mathrm{m} / \mathrm{e} 114$ (Ana pik, \% 100)
6) $\mathrm{m} / \mathrm{e} 150\left(\mathrm{M}^{+}-144, \% 71.87\right)$

12. 2-Düzopropilaminoetil o-nitrobenzoat Hidroklorür (Bileşik: 34)

Genel yönteme göre yapılan sentezde $5.01 \mathrm{~g}$ o-nitrobenzoik asit, 6.00 g 2-diizopropilaminoetil klorür hidroklorür ve $6.07 \mathrm{~g}$ trietilamin kullanıldı. Sentez sonunda 7.25 g saf bileşik elde edildi. (Verim: \% 70.02)

\section{E. N.: $178.9^{\circ} \mathrm{C}$}

UV Spektrumu: $\lambda$ maks. $212(\varepsilon=5000)$ ve $260 \mathrm{~nm}(\varepsilon=150)$

N M R Spektrumu: $\delta$ ppm. 1.43 (izopropil gruplarının metil protonları, $12 \mathrm{H}$, dd), 3.40-4.20 (azot atomuna bağlı metilen ve metin protonları, 4H, m), 4.90 (oksijen atomuna bağlı metilen protonları, $2 \mathrm{H}, \mathrm{t}$ ), 8.40 (benzen halkasının tüm protonları, $4 \mathrm{H}, \mathrm{m}$ ) 
Kütle Spektrumu:

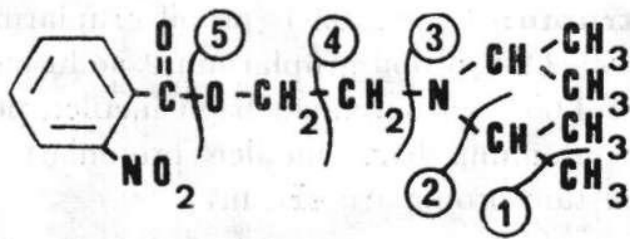

M $^{+} 294$ Moleküler iyon, \% 55. 11)

1) $\mathrm{m} / \mathrm{e} 279\left(\mathrm{M}^{+}-15, \% 92.91\right)$

2) $\mathrm{m} / \mathrm{e} 251 \quad\left(\mathrm{M}^{+}-43, \% 22.05\right)$

3) $\mathrm{m} / \mathrm{e} 194\left(\mathrm{M}^{+}-100, \% 80.31\right)$

4) $\mathrm{m} / \mathrm{e} 114$ (Ana pik, \% 100)

5) $\mathrm{m} / \mathrm{e} 150\left(\mathrm{M}^{+}-144, \% 89.76\right)$

13. 2-Di-n-butilaminoetil o-nitrobenzoat Hidroklorür (Bileşik: 35)

Genel yönteme göre yapılan sentezde $5.01 \mathrm{~g}$ o-nitrobenzoik asit, $6.84 \mathrm{~g}$ 2-di-n-butilaminoetil klorür hidroklorür ve $6.07 \mathrm{~g}$ trietilamin kullanıldı. Sentez sonunda 7.53 g saf bileşik elde edildi. (Verim: \% $70.02)$

E. N.: $133 .{ }^{\circ} \mathrm{C}$

UV Spektrumu: $\lambda$ maks. $212(\varepsilon=1450)$ ve $260 \mathrm{~nm}(\varepsilon=200)$

NM R Spektrumu: $\delta$ ppm. 0.92 (butil gruplarının metil protonlar1, $6 \mathrm{H}, \mathrm{t}$ ), 1.10-2.20 (butil gruplarının 2 ve 3 no.lu metilen protonları, 8H, m), 3.00-4.00 (azot atomuna bağlı metilen protonları, $6 \mathrm{H}, \mathrm{m}$ ), 4.95 (oksijen atomuna bağlı metilen protonları, $2 \mathrm{H}, \mathrm{t}$ ), 8.40 (benzen halkasının tüm protonları, 4H, m).

\section{Kütle Spektrumu:}

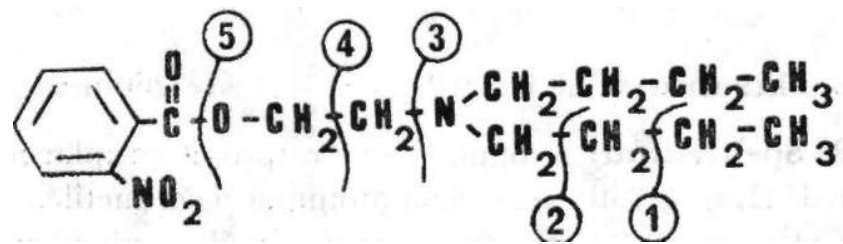

$\mathrm{M}^{+} 322$ (Moleküler iyon. \% 40. 62) 

1) $\mathrm{m} / \mathrm{e} 293\left(\mathrm{M}^{+}-29, \% 15.62\right)$
2) $\mathrm{m} / \mathrm{e} 279 \quad\left(\mathrm{M}^{+}-43, \% 96.87\right)$
3) $\mathrm{m} / \mathrm{e} 194\left(\mathrm{M}^{+}-128, \% 84.37\right)$
4) $\mathrm{m} / \mathrm{e} 142$ (Ana pik, \% 100)
5) $\mathrm{m} / \mathrm{e} 150\left(\mathrm{M}^{+}-172, \% 78.12\right)$

\section{SONUÇ ve TARTIŞMA}

$\mathrm{Bu}$ çalışmada, benzoik asit esteri lokal anestezik bileşiklerde orto konumundaki sübstitüentlerin biyolojik etkiye katkılarını ortaya koymak üzere sentezlenen ve sadece orto veya para konumunda grup içeren türevlerin sentez ve yapı açıklamaları ele alınmıştır. Bu tip esterlerin literatürde en fazla rastlanan sentez yöntemi asit klorürler ile dialkilaminoetanollerin birleştirilmesidir. Asit klorürlerin hazırlanmasında, orto konumundan sübstitüent içeren asitlerde tiyonil klorür veya fosfor pentaklorür ile klorlama sterik engeller nedeniyle çok zor ve düşük verimle yapılabildiğinden asitlerin yerine alkollerin klorlanması tercih edilmiştir. Bu durumda, esterleşme uzun süren reaksiyon şartlarında olmasına karşın çok saf bileşikler elde edilebilmektedir.

Sentezlenen 40 bileşiğin 13 tanesi ilk kez bu çalışmada yapılmıştır. Daha önce yapılan bileşiklerin, literatürdeki verilere uygunlu$\breve{g u}$ tesbit edilmiş, ancak, bu bileşikler de dahil olmak üzere tümünün aletsel analiz yöntemleri ile yapıları kanıtlanmıştır. Çalışmada, sadece ilk kez yapılan bileşiklerin aletsel analiz çalışmaları sonucu bulunan verileri gösterilmiştir.

\section{ÖZET}

Bu çalışmada yapı-etki ilişkilerinin incelenmesi amacıyla sentezlenen ve sadece orto veya para konumundan sübstitüent içeren benzoik asit esteri lokal anestezik bileşiklerin sentez yöntemleri ve bu amaçla sentezlenen 40 bileşikten ilk kez yapılan 13 adetinin UV, İR, N M R ve Kütle Spektroskopisi yöntemleri ile yapı açıklamaları verilmiştir.

\section{SUMMARY}

In this research, 40 esters of para or ortho substituted benzoic acids possessing local anesthetic activity are synthetised and 13 of them were original. The chemical structure of original compounds had been eludicated by their UV, IR, NMR and Mass Spectra. 


\section{LİTERATÜR}

1- Ladenburg, A., Chem. Ber., 14, 1876 - 80 (1881).

2- Knorr, L., Matthes, H., Chem. Ber., 31, 1069-77 (1898).

3- Knorr, L., Chem Ber., 37, 3507-11 (1904).

4- Karrer, P., Horlacher, E., Loeher, F., Giesler, M., Chem. Ber., 57, $905-19$ (1924).

5- Abramson, D.L., Goldberg, S.D., J. Pharmacol. Exptl. Therap., 62, 69-87 (1933).

6- Goldberg, S.D., Whitmore, W.F., J.Am. Chem. Soc, 59, 2280-2 (1937).

7- Goldberg, S.D., Ringk, W.F., Spoerri, P.E., J.Am.Chem.Soc, 61, 3562-3 (1939).

8- Kremer, C.B., Waldman, E., J.Am.Chem.Soc, 64, 1089-90 (1942).

9- Ringk, W.F., Epstein, E., J.Am.Chem.Soc, 65, 1222-6 (1943).

10- Cope, A.C., Hancock, E.M., J.Am.Chem.Soc, .66, 1453-6 (1944).

11- Hancock, E.M., Cope, A.C., J.Am.Chem.Soc, 66, 1738-42 (1944).

12- Hancock, E.M., Hardy, E.M., Heyl, D., Wright, M.E., Cope, A.C., J.Am.Chem. Soc, 66, 1742-52 (1944).

13- Reasenberg, J.R., Goldberg, S.D., J.Am.Chem.Soc, 67, 933-9 (1945).

14- Mc Elvain, S.M., Carrey, T.P., J.Am.Chem.Soc, 68, 2592-600 (1946).

15- Bandelin, J.F., Tuschoff, J.V., J.Am.Pharm.Assoc, 40, 202-4 (1951).

16- Anderson, E.L., Wilson, J.W., Ullyot, G.E., J.Am.Pharm.Assoc, Sci., Ed., 41, 64350 (1952).

17- Epstein, E., Meyer, M., J.Am.Chem.Soc, 77, 4059-61 (1955).

18- Detrie, J.A.H., Fr.Pat., 1, 234, 70119 Oct 1960.

19- Valette, G., Medicaments Organique de Synthese, Masson et Cie., Paris, 1970.

20- Chemische Fabrik auf Aktien, Ger.Pat. 175, 08021 Sep 1904, Chem.Abstr., 1, 925 (1907).

21 - Vatlina, L.P., Takhistov, V.V., Temnikova, T.I., Friedlynanskii, G.V., Zh. Vses.Khim. Obschest., 17 (2), 233 (1972).

22- Eogatkov, S., Igumnova, N.D., Kruglikova, R.I., Kundryotskova, L.A., Cherkasova, E.M., Biokhimiya, 39 (1), 135-40 (1974).

23 - Vatlina, L.P., Takhistov, V.V., Uch. Zap- Krosl. Gos. Pedagog. Inst., 151, $61-5$ (1975).

24- Cook, E.S., Kreeke, C.W., J.Am.Chem.Soc., 62, 1951-3 (1940).

25- Vanderhaeghe, H., Kolosy, P., Claesen, M.,J.Pharm. Pharmacol., 6, 119-26 (1954).

26- Rohmann, C, Scheurle, B., Arch. Pharm., 274, 225-35 (1936).

27- Reynaud, P., Moreau, R.C., Bourinet, P., Maziere, B., Quevauviller, A., Chim. Ther., 2 (1), 25-32 (1967).

28 - Laubender, W., Lübenberg, L., Arzneim.Forsch., 14, 445-50 (1964).

29- Rohmann, C, Frank., D., Eckert, Th., Arzneim.Forsch., 15 (4), 388-91 (1965)..

30- Einhorn, A., Fiedler, K., Ladisch, C, Uhfelder, E., Ann. Chem., 371, 142-61 (1909). 
31 - Burnett, W.B., Jenkins, R.L., Peet, C.H., Dreger, E.E., Adams, R., J.Am.Chem. Soc., 59, 2248-52 (1937).

32- Einhorn, A., Uhfelder, E., Ann.Chem., 371, 131-42 (1909).

33- Perlia, X., Pharm. Acta Helv., 42 (8-10), 517-33 (1967).

34- Bülbring, E., Wajda, I., J. Pharmacol. Exptl. Therap., 85, 78-84 (1945).

35- Markaryan, E.A., Arakalyan, E.A., Khorenyan, G.K., Arm.Khim.Zh., 25 (7), 598-603 (1972).

36- Einhorn, A., Ger..Pat., 812, 55413 Feb 1906.37-Büchi, J ., Bruhin, H.K., Perlia, X., Arzneim.Forsch. \{Drug Re

38- Schmitz, H.L., Loevenhart, A.S., J.Pharmacol. Exptl. Therap., 24, 167-77 (1925).

39- Thomas, J., Canty, J., J. Pharm. Pharmacol, 14, 587-96 (1962).

40- Schering - Kahlbaum A.G., Ger. Pat., 522, 06404 Apr 1931.

41 - Kigasawa, K., Ohteni, H., Yakugaku Zasshi, 96(1), 6-11 (1976).

42- Hirata, M., Isoda, S., Kanao, M., Shimizu, H., Inoue, S., Bull. Jap. Soc.Sci., Fish., 36(11), 1127-35 (1970). 